\title{
HUBUNGAN KONSUMSI SUGAR-SWEETENED BEVERAGES DENGAN KEJADIAN DIABETES MELLITUS PADA LANSIA
}

\author{
The Correlation Between Sugar-Sweetened Beverages Consumption and Diabetes mellitus \\ in Elderly
}

\author{
Putri Ramadhani ${ }^{*}$, Trias Mahmudiono ${ }^{2}$ \\ ${ }^{1-2}$ Departemen Gizi Kesehatan, Fakultas Kesehatan Masyarakat, Universitas Airlangga \\ Kampus C Unair Jalan Mulyorejo Surabaya, Jawa Timur, Indonesia \\ E-mail: putriramadhani2393@gmail.com
}

\begin{abstract}
ABSTRAK
Kelompok usia lanjut (lansia) menjadi kelompok yang paling berisiko terkena Diabetes mellitus Tipe 2 (DM) karena kelompok ini merupakan populasi yang rentan terhadap gangguan metabolisme karbohidrat yang dapat muncul sebagai DM. Penelitian ini bertujuan untuk mengetahui hubungan antara konsumsi sugar-sweetened beverages (SSB) dan jenis kelamin dengan kejadian DM pada lansia. Populasi dalam penelitian ini adalah semua penduduk lansia (usia > 60 tahun) di wilayah kerja Puskesmas Jagir. Penelitian ini menggunakan desain case control dengan teknik pengambilan sampel yaitu simple random sampling. Jumlah sampel yang diteliti adalah 78 responden dengan sampel kasus sebanyak 39 orang dan sampel kontrol sebanyak 39 responden. Analisis data menggunakan uji regresi linier dan regresi logistik. Hasil penelitian menunjukkan bahwa ada hubungan antara konsumsi SSBs (gula pasir) dengan kejadian diabetes mellitus pada lansia $(\mathrm{p}=0,000 ; \mathrm{OR}=9,375)$. Lansia dengan jenis kelamin wanita lebih banyak mengonsumsi SSBs dibandingkan dengan lansia laki-laki (konsumsi gula pasir wanita 26,9\%, gula merah 69,2\%, sirup 75,6\% dan minuman sachet 73,1\%; sedangkan konsumsi gula pasir laki-laki 9\%, gula merah 20,5\%, sirup 16,7\% dan minuman sachet 15,4\%). Kesimpulan dalam penelitian ini adalah ada hubungan antara konsumsi SSBs dengan kejadian DM pada lansia serta konsumsi SSBs pada wanita lebih tinggi dibandingkan laki-laki.
\end{abstract}

Kata kunci: sugar-sweetened beverages (SSBs), diabetes mellitus (DM), lansia

\begin{abstract}
Elderly becomes the most risky group in developing type 2 diabetes because they are more susceptible for carbohydrate metabolism disorders that can appear as diabetes. This study was aimed to determine the correlation between consumption of sugar-sweetened beverages and sex with the incidence of diabetes mellitus in the elderly. The population in this study were all elderly population (age > 60 years) in Jagir Public Health Center working area. This research used case control design with simple random sampling technique as a sampling method. The number of samples was 78 respondents with 39 samples of case group and 39 samples of control group. Data were analyzed using linear regression and logistic regression test. The results showed that there was a correlation between the consumption of SSBs and the incidence of diabetes mellitus in elderly $(p=0.000 ;$ OR $=9.375)$. Female elderly consumed more SSBs than men elderly (female's sugar consumption 26.9\%, brown sugar 69.2\%, syrup 75.6\% and sachet drinks $73.1 \%$, while mal's sugar consumption 9\%, brown sugar 20.5\%, syrup 16.7\% and sachet drinks 15.4\%). In conclusion, this research revealed consumption of SSB's was higher in female elderly and SSB's consumption was correlated with the incidence of type 2 diabetes mellitus.
\end{abstract}

Keywords: sugar-sweetened beverages (SSBS), diabetes mellitus (DM), elderly

\section{PENDAHULUAN}

Diabetes mellitus (DM) merupakan salah satu penyakit degeneratif yang ditandai dengan meningkatnya kadar glukosa di dalam darah akibat adanya gangguan pada sekresi insulin dan kerja insulin yang dapat berdampak terhadap kerusakan jangka panjang, disfungsi organ serta kegagalan kerja organ lain di dalam tubuh (American Diabetes Association, 2014). Berdasarkan data dari International Diabetes Federation (IDF) tahun 
2013 diketahui bahwa sebanyak 382 juta orang di dunia menderita DM dimana pada tahun 2035 diperkirakan akan terjadi peningkatan prevalensi DM menjadi sekitar 592 juta orang. Diperkirakan dari 382 juta orang yang mengalami DM, sebanyak 175 juta diantaranya belum terdiagnosis sehingga terancam berkembang secara progresif menjadi komplikasi yang tanpa disadari dan tanpa disertai dengan pencegahan (Kemenkes RI, 2015). Data dari International Diabetes Federation (2015) menunjukkan bahwa terdapat sekitar 10 juta kasus diabetes di Indonesia pada tahun 2015 dimana sebanyak 6,2\% kasus DM terjadi pada orang dewasa dengan rentang umur 20-79 tahun.

Data dari Kemenkes RI (2015) menunjukkan bahwa terjadi peningkatan prevalensi DM di Indonesia dalam beberapa dekade terakhir. Kurniawan (2010) menjelaskan bahwa prevalensi Diabetes mellitus akan meningkat seiring dengan bertambahnya usia, yang kemudian menetap dan pada akhirnya menurun. Hal ini disebabkan karena seiring dengan pertambahan usia, maka lanjut usia (lansia) akan mengalami kemunduran fisik dan mental yang kemudian menimbulkan banyak konsekuensi terkait metabolisme tubuh. Kelompok usia lanjut menjadi kelompok yang paling berisiko terkena DM karena kelompok usia lanjut merupakan populasi yang rentan terhadap gangguan metabolisme karbohidrat yang dapat muncul sebagai DM. Pada usia lanjut, DM sering tidak disadari karena gejala klinisnya tidak spesifik sehingga baru disadari pada saat muncul penyakit lain atau penyakit kronis (Nainggolan, et al., 2013).

Masalah kesehatan yang sering timbul pada usia lanjut yaitu masalah gizi lebih atau obesitas yang memicu timbulnya penyakit degeneratif, seperti jantung koroner, diabetes melitus, hipertensi, gout, reumatik, ginjal, sirosis hati, empedu dan kanker. Selain itu, proses metabolisme yang menurun pada usia lanjut menyebabkan terjadinya peningkatan risiko kejadian obesitas pada lansia. Obesitas akan meningkatkan risiko menderita penyakit jantung koroner 1-3 kali; hipertensi 1,5 kali; diabetes mellitus 2,9 kali; dan penyakit empedu 1-6 kali (Adriani dan Wirjatmadi, 2012). Selain itu, pada usia lanjut terjadi penurunan indera perasa, penciuman, pendengaran, penglihatan dan perabaan. Selain itu, sensitivitas terhadap rasa manis dan asin juga akan berkurang sehingga menyebabkan lansia senang mengonsumsi makanan dan minuman yang manis (sugar-sweetened beverages) sehingga lansia berisiko mengalami penyakit degeneratif seperti diabetes mellitus dan hipertensi (Kemenkes RI, 2011). Kumar, et al., (2014) menjelaskan bahwa konsumsi SSBs harian berkaitan dengan kejadian obesitas dan penyakit kronis lainnya, seperti diabetes mellitus dan penyakit kardiovaskular.

Penelitian ini bertujuan untuk mengetahui hubungan antara konsumsi sugar-sweetened beverages (SSBs) dan jenis kelamin dengan kejadian diabetes mellitus pada lansia di wilayah kerja Puskesmas Jagir Surabaya.

\section{METODE}

Penelitian ini termasuk jenis penelitian observasional analitik dengan desain case control, dengan kelompok kasus adalah lansia penderita diabetes mellitus dan kelompok kontrol adalah lansia yang tidak menderita diabetes mellitus (non DM). Penelitian ini dilakukan di wilayah kerja Puskesmas Jagir Surabaya pada Juli-September 2017.

Penelitian ini dilakukan di lima Posyandu Lansia yang berada di wilayah kerja Puskesmas Jagir Kota Surabaya dimana pemilihan posyandu dilakukan secara acak dari 18 posyandu lansia yang ada di wilayah Jagir Kota Surabaya. Proses wawancara serta pengukuran berat badan dan tinggi badan dilakukan di balai posyandu lansia.

Populasi dalam penelitian ini adalah semua penduduk lansia (usia $>60$ tahun) yang terdaftar di wilayah kerja Puskesmas Jagir. Sampel terdiri dari 39 orang lansia sebagai kelompok kasus dan 39 orang sebagai kelompok kontrol, sehingga jumlah sampel secara keseluruhan yaitu 78 orang lansia. Kriteria inklusi dalam penelitian ini yaitu: sampel berusia 60-74 tahun, tidak pikun atau lansia masih memiliki daya ingat yang baik, terdaftar sebagai penduduk asli di wilayah kerja Puskesmas Jagir Kota Surabaya, berada di wilayah kerja Puskesmas Jagir Kota Surabaya pada saat pengambilan data. Kriteria eksklusi pada penelitian ini yaitu sampel yang telah pindah ke daerah lain atau telah meninggal. 
Teknik pengambilan sampel pada penelitian ini adalah sampel acak sederhana (simple random sampling). Cara penentuan sampel terlebih dahulu dengan mencari kasus dari data sekunder yang diperoleh dari data lansia Puskesmas Jagir tahun 2016, dimana lansia yang memenuhi syarat inklusi dan bersedia diwawancara dipilih secara acak untuk dijadikan sampel. Lansia yang menderita diabetes mellitus akan menjadi sampel kelompok kasus dan lansia yang tidak menderita diabetes mellitus akan menjadi sampel kelompok kontrol dengan pengambilan acak 1:1.

Variabel dependent dalam penelitian ini yaitu kejadian diabetes mellitus pada lansia yang dikelompokkan menjadi penderita diabetes mellitus dan non diabetes mellitus dimana data terkait lansia penderita diabetes mellitus dan non diabetes mellitus (jenis kelamin, usia, alamat, dan status DM) diperoleh melalui data sekunder Puskesmas Jagir Kota Surabaya. Sedangkan variabel independent dalam penelitian ini yaitu konsumsi sugar-sweetened beverages (SSB's) seperti gula pasir, gula merah, sirup dan minuman sachet, yang diperoleh melalui instrumen kuesioner Food Frequency khusus diabetes mellitus. Selain itu, variabel yang diteliti yaitu karakteristik individu (meliputi pendidikan, pekerjaan, usia dan jenis kelamin), pengetahuan gizi dan sikap lansia yang diperoleh melalui wawancara kepada lansia menggunakan kuesioner serta status gizi yang diperoleh melalui pengukuran berat badan (BB) menggunakan timbangan digital CAMRY dengan ketelitian $0,1 \mathrm{~kg}$ dan tinggi badan menggunakan microtoise GEA dengan ketelitian $0,1 \mathrm{~cm}$.

Analisis data terdiri dari analisis univariat, bivariat dan multivariat. Analisis univariat dilakukan dengan tujuan melihat gambaran distribusi frekuensi dan proporsi dari variabel independen dan variabel dependen. Analisis bivariat dilakukan untuk mengetahui hubungan variabel independent dan dependent dengan menggunakan uji regresi linier, jika $\mathrm{p}<0,05$ maka terdapat hubungan antara kedua variabel. Selanjutnya, dilakukan analisis multivariat terhadap variabel yang memiliki hubungan atau signifikan untuk mengetahui variabel mana yang memiliki pengaruh paling besar terhadap kejadian diabetes mellitus pada lansia. Uji statistik yang digunakan untuk analisis multivariat yaitu uji regresi logistik ganda yang digunakan untuk menganalisis hubungan variabel independen dengan variabel dependen yang bersifat kategorik.

\section{HASIL DAN PEMBAHASAN}

\section{Karakteristik Responden}

Berdasarkan Tabel 1, diketahui bahwa sebagian besar responden kelompok kasus maupun kelompok kontrol memiliki pendidikan terakhir SMA, dengan persentase kelompok kasus yaitu sebesar 17,8\%, sedangkan kelompok kontrol sebesar $21,8 \%$.

Sebagian besar responden baik kelompok kasus maupun kelompok kontrol tidak bekerja dengan persentase kelompok kasus sebesar 34,6\% dan kelompok kontrol sebesar 32,1\%. Sebagian besar usia responden terletak pada Quintil 5, yang berkisar antara 69 tahun hingga 74 tahun dengan persentase kelompok kasus dan kelompok kontrol masing-masing adalah 16,7\%. Sebagian besar responden berjenis kelamin perempuan, dimana persentase responden perempuan pada kelompok kasus yaitu sebesar 34,6\% dan responden laki-laki sebesar $15,4 \%$, sedangkan pada kelompok kontrol, responden dengan jenis kelamin perempuan yaitu sebanyak $44,9 \%$ dan responden dengan jenis kelamin laki-laki sebesar 5,1\%. Lama menderita penyakit diabetes mellitus pada responden kelompok kasus, sebagian besar terletak pada Quintil 5, yaitu berkisar antara 5,5 tahun sampai 45 tahun. Sebagian besar pengetahuan responden terkait indeks glikemik makanan berada pada kategori kurang dengan persentase kelompok kasus yaitu sebesar 39,7\%, sedangkan pada kelompok kontrol yaitu sebesar $41 \%$. Sebagian besar sikap responden berada pada Quintil 5, dengan rentang skor antara 62,4-78, dimana kelompok kasus yang berada pada Quintil 5 sebesar 14,1\%, sedangkan pada kelompok kontrol yaitu sebesar 23,1\%. Sebagian besar responden baik kelompok kasus maupun kelompok kontrol memiliki status gizi normal, dengan persentase kelompok kasus sebesar $24,3 \%$ dan kelompok kontrol sebesar $29,4 \%$. 
Tabel 1. Distribusi Karakteristik Individu

\begin{tabular}{|c|c|c|c|c|c|c|}
\hline \multirow{2}{*}{ Variabel } & \multicolumn{2}{|c|}{ Kasus } & \multicolumn{2}{|c|}{ Kontrol } & \multicolumn{2}{|c|}{ Total } \\
\hline & $\mathbf{n}$ & $\%$ & $\mathbf{n}$ & $\%$ & $\mathbf{n}$ & $\%$ \\
\hline \multicolumn{7}{|l|}{ Pendidikan } \\
\hline Tidak Sekolah & 1 & 1,3 & 3 & 3,8 & 4 & 5,1 \\
\hline $\mathrm{SD}$ & 8 & 10,3 & 7 & 9 & 15 & 19,3 \\
\hline SMP & 8 & 10,3 & 8 & 10,3 & 16 & 20,6 \\
\hline SMA & 14 & 17,8 & 17 & 21,8 & 31 & 39,6 \\
\hline Perguruan Tinggi & 8 & 10,3 & 4 & 5,1 & 12 & 15,4 \\
\hline \multicolumn{7}{|l|}{ Pekerjaan } \\
\hline Swasta & 1 & 1,3 & 0 & 0 & 1 & 1,3 \\
\hline Wiraswasta & 3 & 3,8 & 5 & 6,4 & 8 & 10,2 \\
\hline Pensiunan & 8 & 10,3 & 9 & 11,5 & 17 & 21,8 \\
\hline Tidak Bekerja & 27 & 34,6 & 25 & 32,1 & 52 & 66,7 \\
\hline \multicolumn{7}{|l|}{ Usia } \\
\hline Q1: 60-61 & 4 & 5,1 & 10 & 12,8 & 14 & 17,9 \\
\hline Q2: 62-63 & 4 & 5,1 & 5 & 6,4 & 9 & 11,5 \\
\hline Q3: 64-65 & 6 & 7,7 & 4 & 5,1 & 10 & 12,8 \\
\hline Q4: 66-67 & 10 & 12,8 & 4 & 5,1 & 14 & 17,9 \\
\hline Q5: 68-69 & 4 & 5,1 & 5 & 6,4 & 9 & 11,5 \\
\hline Q6: 70-71 & 3 & 3,8 & 4 & 5,1 & 7 & 9,0 \\
\hline Q7: 72-73 & 4 & 5,1 & 4 & 5,1 & 8 & 10,3 \\
\hline Q8: 74-75 & 4 & 5,1 & 3 & 3,8 & 7 & 9,0 \\
\hline \multicolumn{7}{|l|}{ Jenis Kelamin } \\
\hline Laki-laki & 12 & 15,4 & 4 & 5,1 & 16 & 20,5 \\
\hline Perempuan & 27 & 34,6 & 35 & 44,9 & 62 & 79,5 \\
\hline \multicolumn{7}{|l|}{ Lama DM } \\
\hline Q1: 0-1 & 7 & 8,9 & 39 & 50 & 46 & 58,9 \\
\hline Q2: 1.5-2 & 4 & 5,2 & 0 & 0 & 4 & 5,2 \\
\hline Q3: 2.5-5 & 3 & 3,9 & 0 & 0 & 3 & 3,9 \\
\hline Q4: 5.5-45 & 25 & 32 & 0 & 0 & 25 & 32 \\
\hline \multicolumn{7}{|l|}{ Pengetahuan } \\
\hline Cukup & 8 & 10,3 & 7 & 9 & 15 & 19,3 \\
\hline Kurang & 31 & 39,7 & 32 & 41 & 63 & 80,7 \\
\hline \multicolumn{7}{|l|}{ Sikap } \\
\hline Q1: 40-44 & 5 & 6,4 & 2 & 2,6 & 7 & 9,0 \\
\hline Q2: 45-49 & 7 & 9,0 & 3 & 3,8 & 10 & 12,8 \\
\hline Q3: 50-54 & 4 & 5,1 & 6 & 7,7 & 10 & 12,8 \\
\hline Q4: 55-59 & 5 & 6,4 & 6 & 7,7 & 11 & 14,1 \\
\hline Q5: 60-64 & 11 & 14,1 & 10 & 12,8 & 21 & 26,9 \\
\hline Q6: 65-69 & 7 & 9,0 & 9 & 11,5 & 16 & 20,5 \\
\hline Q7: $70-74$ & 0 & 0,0 & 1 & 1,3 & 1 & 1,3 \\
\hline Q8: 75-79 & 0 & 0,0 & 2 & 2,6 & 2 & 2,6 \\
\hline \multicolumn{7}{|l|}{ Status Gizi } \\
\hline Kurus & 0 & 0 & 1 & 1,3 & 1 & 1,3 \\
\hline Normal & 19 & 24,3 & 23 & 29,4 & 42 & 53,7 \\
\hline Gemuk & 7 & 9 & 7 & 9 & 14 & 18 \\
\hline Obese & 13 & 16,7 & 8 & 10,3 & 21 & 27 \\
\hline
\end{tabular}

Hubungan Pengetahuan, Sikap dan Perilaku Lansia dengan Kejadian Diabetes mellitus

Pengetahuan tentang kesehatan dapat membantu seseorang dalam menindaklanjuti penyakit yang sedang diderita, memudahkan seseorang untuk beradaptasi dengan penyakitnya, mencegah komplikasi dan mematuhi program terapi yang telah ditentukan (Notoatmodjo, 2010). Hal ini didukung oleh penelitian Gultom (2012) yang menunjukkan bahwa kepatuhan diet tergantung dari tingkat pengetahuan pasien yang menentukan kesadaran pasien untuk patuh terhadap diet yang dianjurkan oleh tim kesehatan. 
Dengan meningkatnya pengetahuan pasien, maka diharapkan terjadi peningkatan kesadaran diri dari segi kesehatan, mengubah gaya hidup ke arah yang sehat, patuh terhadap terapi, dan hidup berkualitas. Namun, tabel 2 menunjukkan bahwa tidak ada hubungan yang signifikan antara pengetahuan dengan kejadian diabetes mellitus pada lansia $(\mathrm{p}>0,05)$. Hal ini menunjukkan bahwa tinggi atau rendahnya pengetahuan lansia terkait DM tidak berpengaruh terhadap kejadian diabetes mellitus.

Sikap adalah suatu respons atau reaksi seseorang dari suatu stimulus yang diberikan dan akan mendasari seseorang tersebut untuk melakukan sesuatu untuk menimbulkan perilaku (Rusmanto, 2013). Berdasarkan tabel 2, diketahui bahwa pada penelitian ini sikap lansia tidak memiliki hubungan yang bermakna dengan kejadian diabetes mellitus $(\mathrm{p}>0,05)$. Hal ini menunjukkan bahwa tinggi atau rendahnya sikap lansia terhadap penatalaksanaan DM tidak berpengaruh terhadap kejadian DM.

Berdasarkan penelitian yang terdapat pada tabel 2, dapat diketahui bahwa perilaku konsumsi gula pasir harian memiliki hubungan yang signifikan dengan kejadian diabetes mellitus pada lansia $(\mathrm{p}<0,05)$. Berdasarkan uji regresi logistik, diketahui bahwa lansia yang lebih sering mengonsumsi gula pasir harian memiliki risiko terkena diabetes mellitus sebanyak 9,375 kali dibandingkan dengan lansia yang hanya mengonsumsi gula pasir bulanan.

Hal ini sejalan dengan penelitian Murti (2016) yang meneliti tentang hubungan kebiasaan konsumsi gula dengan kejadian diabetes mellitus di Kabupaten Semarang, yang menunjukkan bahwa orang yang memiliki kebiasaan konsumsi gula lebih banyak memiliki risiko sebesar 3,9 kali menderita diabetes mellitus dibandingkan dengan orang yang konsumsi gulanya lebih sedikit. Konsumsi gula yang berlebihan dapat berdampak terhadap peningkatan berat badan, yang jika dilakukan dalam jangka panjang akan meningkatkan kadar gula darah sehingga menyebabkan terjadinya penyakit diabetes tipe 2 (Kemenkes, 2014). Terjadinya peningkatan berat badan berisiko terhadap kejadian obesitas, yaitu terjadinya kelebihan energi di dalam tubuh yang kemudian akan disimpan dalam bentuk jaringan lemak. Tingginya penumpukan lemak di dalam tubuh dapat menyebabkan terjadinya resistensi insulin yang kemudian akan memengaruhi kadar glukosa di dalam darah (Perkeni, 2015).

Gula yang dikonsumsi masyarakat tidak hanya terdapat pada gula pasir, gula tebu, maupun gula merah saja. Namun, kandungan gula juga terdapat

Tabel 2. Hubungan Pengetahuan, Sikap dan Perilaku Lansia dengan Kejadian Diabetes Mellitus pada Lansia

\begin{tabular}{|c|c|c|c|c|c|c|}
\hline Variabel & & Rata-Rata Skor & SD & OR & $95 \% \mathrm{CI}$ & p-value \\
\hline \multirow[t]{5}{*}{ Kategori Skor Pengetahuan } & Q1 & & & 0,919 & $0,257-3,283$ & 0,897 \\
\hline & Q2 & & & 0,443 & $0,094-2,090$ & 0,304 \\
\hline & Q3 & 3,2949 & 1,53833 & 1,477 & $0,317-6,895$ & 0,620 \\
\hline & Q4 & & & 3,073 & $0,831-11,355$ & 0,092 \\
\hline & Q5* & & & & & \\
\hline \multirow[t]{5}{*}{ Kategori Skor Sikap } & Q1 & & & 0,34 & $0,090-1,278$ & 0,11 \\
\hline & Q2 & & & 0,407 & $0,094-1,773$ & 0,231 \\
\hline & Q3 & 3,4103 & 1,53264 & 0,978 & $0,255-3,756$ & 0,974 \\
\hline & Q4 & & & 0,306 & $0,074-1,258$ & 0,101 \\
\hline & Q5* & & & & & \\
\hline \multicolumn{7}{|l|}{ Perilaku Konsumsi } \\
\hline \multirow{4}{*}{ Gula pasir } & Harian & & & 9,375 & $2,914-30,163$ & 0,000 \\
\hline & Mingguan & 1,9359 & 0,88772 & 2,100 & $0,578-7,630$ & 0,260 \\
\hline & Bulanan* & & & & & \\
\hline & Harian & & & 1710502775 & $0,000-$ & 1,000 \\
\hline Gula merah & $\begin{array}{l}\text { Mingguan } \\
\text { Bulanan* }\end{array}$ & 2,8864 & 0,35968 & 1,412 & $0,294-6,776$ & 0,667 \\
\hline Sirup & $\begin{array}{l}\text { Mingguan } \\
\text { Bulanan* }\end{array}$ & 2,9231 & 0,26819 & 0,473 & $0,081-2,747$ & 0,404 \\
\hline
\end{tabular}

*References group 
pada makanan yang mengandung karbohidrat sederhana (tepung, roti, kecap) dan minuman lain yang mengandung gula, seperti minuman bersoda, sirup, dan lain-lain, yang dikelompokkan menjadi Sugar-Sweetened Beverages (SSBs) (Kemenkes, 2014).

Penelitian Wang, et al. (2014) tentang hubungan antara sugar-sweetened beverages dengan kejadian diabetes mellitus menunjukkan bahwa ada hubungan yang bermakna konsumsi minuman manis (SSBs) dengan risiko kejadian diabetes mellitus (RR 1,30, 95\% CI 1,21-1,39), dimana orang yang mengonsumsi SSBs lebih banyak memiliki risiko menderita diabetes mellitus sebanyak 1,3 kali dibandingkan orang yang mengonsumsi SSBs lebih sedikit.

\section{Frekuensi Pola Konsumsi Sugar-Sweetened Beverages Berdasarkan Jenis Kelamin}

Gambar 1 menunjukkan frekuensi pola konsumsi SSBs lansia dalam kurun waktu secara harian, mingguan dan bulanan yang dibedakan berdasarkan jenis kelamin.

Berdasarkan gambar 1, dapat diketahui bahwa konsumsi gula pasir harian lebih tinggi pada lansia dengan jenis kelamin perempuan $(35,90 \%)$, sedangkan laki-laki lebih banyak mengonsumsi gula pasir dengan frekuensi bulanan $(6,40 \%)$.

Konsumsi gula merah, sirup dan minuman sachet pada lansia perempuan maupun laki-laki lebih banyak pada frekuensi bulanan, dimana konsumsi gula merah bulanan pada wanita $69,20 \%$ dan laki-laki sebesar 20,50\%. Konsumsi sirup bulanan pada perempuan yaitu $75,60 \%$ dan pada laki-laki sebesar $16,70 \%$. Sedangkan konsumsi minuman sachet bulanan pada perempuan yaitu $73,10 \%$ dan laki-laki sebesar $15,40 \%$.

Data Riskesdas tahun 2013 menunjukkan bahwa proporsi penderita diabetes mellitus pada wanita lebih tinggi dibandingkan dengan proporsi penderita diabetes mellitus pada laki-laki (Kemenkes, 2014). Berdasarkan gambar 1, pada penelitian ini dapat diketahui bahwa konsumsi SSBs pada lansia perempuan lebih tinggi dibandingkan konsumsi SSBs pada lansia laki-laki. Hal ini bertolak belakang dengan penelitian Atmarita et al. (2016) yang menganalisis tentang konsumsi makanan individu tahun 2014 terkait

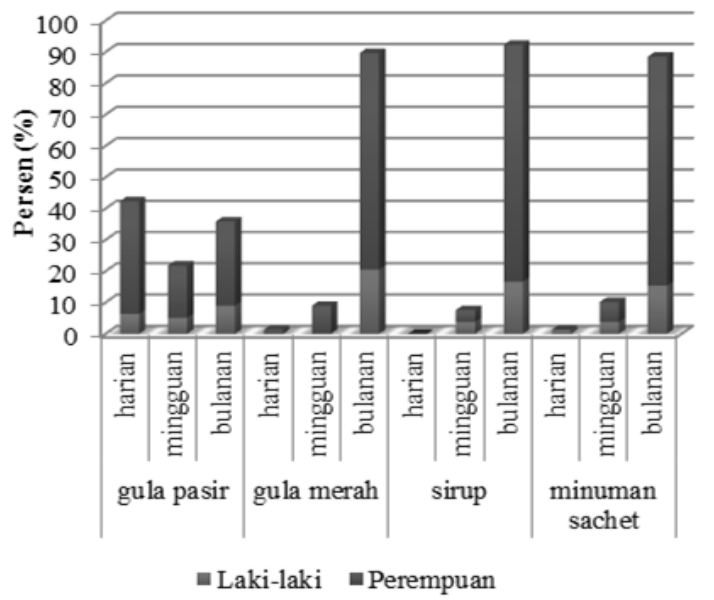

Gambar 1. Persentase Frekuensi Pola Konsumsi Sugar-Sweetened Beverages Berdasarkan Jenis Kelamin

asupan gula, garam dan lemak di Indonesia, dimana penelitian tersebut menunjukkan bahwa konsumsi gula laki-laki pada kelompok umur $>55$ tahun (32,31 gram/orang/hari) cenderung lebih besar dibandingkan perempuan pada kelompok umur $>55$ tahun (23,29 gram/orang/hari). Penelitian ini juga menunjukkan bahwa konsumsi gula tertinggi yaitu terdapat pada kelompok usia $>55$ tahun.

Diabetes mellitus merupakan penyakit kronis yang terjadi baik saat pankreas tidak mampu menghasilkan cukup insulin (hormon yang mengatur gula darah) maupun saat tubuh tidak dapat secara efektif menggunakan insulin yang dihasilkan (WHO, 2016).

Kurniawan (2010) menjelaskan bahwa lansia merupakan populasi yang sangat rentan terhadap gangguan metabolisme karbohidrat yang dapat muncul sebagai diabetes mellitus. Konsumsi SSBs yang berlebihan pada lansia dapat meningkatkan risiko terjadinya diabetes mellitus karena dapat menyebabkan gula tertimbun di dalam darah (hiperglikemia) akibat adanya risiko gangguan metabolisme karbohidrat pada lansia (Adriani dan Witjatmadi, 2012).

\section{KESIMPULAN DAN SARAN}

Kesimpulan dari penelitian ini adalah ada hubungan yang signifikan antara konsumsi SSBs (gula pasir) dengan kejadian diabetes mellitus 
pada lansia. Selain itu, frekuensi pola konsumsi SSBs harian memiliki hubungan yang bermakna terhadap kejadian diabetes mellitus.

Saran yang dapat diberikan adalah perlu dilakukan penelitian lebih lanjut terhadap jenis-jenis makanan yang tergolong SSBs lainnya (seperti minuman bersoda, minuman energi, jus manis, teh manis dan kopi) yang kemungkinan dapat berisiko meningkatkan kejadian diabetes mellitus. Selain itu, dapat dilakukan penelitian terhadap kadar SSBs yang dikonsumsi untuk mengetahui lebih mendalam tentang jumlah konsumsi SSBs yang dapat menyebabkan diabetes mellitus.

\section{DAFTAR PUSTAKA}

Adriani M., \& Wirjatmadi B. (2012). Peranan gizi dalam siklus kehidupan. Jakarta: Kencana Prenadamedia Group.

American Diabetes Association. (2014). Diagnosis and classification of diabetes mellitus. Journal of Diabetes Care, 37(1), 581-590. Diakses dari http://care.diabetesjournals.org/content/37/ Supplement_1/S81.full.

Atmarita, Abas B.J., Sudikno, \& Moesijanti S. (2016). Asupan gula, garam, dan lemak di Indonesia: analisis survey konsumsi makanan individu (SKMI) 2014. Journal of the Indonesian Nutrition Association, 39 (1, 1-14). Diakses dari http://ejournal.persagi.org/ ojspersagi2481/index.php/Gizi_Indon/article/ viewFile/201/178.

Gultom Y.T. (2012). Tingkat pengetahuan pasien diabetes mellitus tentang manajemen diabetes mellitus di rumah sakit pusat angkatan darat Gatot Soebroto Jakarta Pusat (Skripsi, Universitas Indonesia). Diakses dari http:// lib.ui.ac.id/file?file=digital/20314370-S43834 Tingkat\%20pengetahuan.pdf.

International Diabetes Federation. (2013). Indonesia at a glance: extract of the global diabetes scorecard tracking progress for action. Paper presented at International Diabetes Federation, Belgium. Diakses dari http://www.idf.org/ global-diabetes-scorecard/assets/downloads/ Scorecard-29-07-14.pdf.
Kementerian Kesehatan RI. (2011). Buku pedoman pelayanan gizi lanjut usia. Jakarta: Direktorat Jenderal Bina Gizi dan Kesehatan Ibu dan Anak. Diakses dari: http://digilib.poltekkesdepkes-sby. ac.id/public/POLTEKKESSBY-Books-399Pedomanpelayanangizilanjutusia. PDF.

Kementerian Kesehatan RI. (2014). Pedoman gizi seimbang. Jakarta: Direktorat Jenderal Bina Gizi dan Kesehatan Ibu dan Anak. Diakses dari http://www.gizi.depkes.go.id/download/ Pedoman\%20Gizi/PGS\%20Ok.pdf.

Kementerian Kesehatan RI. (2015). Waspada diabetes. Jakarta: Infodatin Pusat Data dan Informasi Kementerian Kesehatan RI. Diakses dari http://www.depkes.go.id/resources/ download/pusdatin/infodatin/infodatindiabetes.pdf.

Kumar G.S., Liping P., Sohyun P., Seung H.L.K., Stephen O., \& Heidi M.B. (2014). Sugarsweetened beverages consumption among adults-18 states, 2012. Journal of Morbidity and mortality weekly report, 63(32), 686-690). Diakses dari https://www.cdc.gov/mmwr/pdf/ wk/mm6332.pdf.

Kurniawan I. (2010). Diabetes melitus tipe 2 pada usia lanjut. Majalah Kedokteran Indonesia, 60(12, 576-584). Diakses dari http://indonesia. digitaljournals.org/index.php/idnmed/article/ download/511/508.

Murti L.Y. (2016). Hubungan antara kebiasaan konsumsi gula dengan kejadian diabetes mellitus di wilayah kerja Puskesmas Leyangan Ungaran Timur Kabupaten Semarang (Skripsi, Sekolah Tinggi Ilmu Kesehatan Ngudi Waluyo Ungaran, Semarang). Diakses dari http://perpusnwu.web. id/karyailmiah/documents/4973.pdf.

Nainggolan O, A Yudi K. \& Hendrik E. (2013). Determinan diabetes melitus analisis baseline data studi kohort penyakit tidak menular Bogor 2011. Buletin Penelitian Sistem Kesehatan, 16(3), 331-339. Diakses dari http:// ejournal.litbang.depkes.go.id/index.php/hsr/ article/view/3471/3435.

Notoatmodjo S. (2010). Ilmu perilaku kesehatan. Jakarta: Penerbit Rineka Cipta.

Perkeni. (2015). Konsensus pengelolaan dan pencegahan diabetes mellitus tipe 2 di Indonesia 2015. Jakarta: PB Perkeni. Diakses dari pbperkeni.or.id/doc/konsensus.pdf. 
Rusmanto. (2013). Faktor-faktoryang memengaruhi sikap dan perilaku masyarakat terhadap kepatuhan minum obat anti filaria di RW II Kelurahan Pondok Aren (Skripsi, Universitas Islam Negeri Syarif Hidayatullah, Jakarta). Diakses dari http://repository.uinjkt.ac.id/dspace/ bitstream/123456789/.../RUSMANTO\%20 -\%20fkik.pdf.
Wang M., Min Y., Le F. \& Ru Y.H. (2014). Association between sugar-sweetened beverages and type 2 diabetes: a meta-analysis. Journal of Diabetes Investigation, 6(3, 360-366). Diakses dari https:/www.ncbi.nlm.nih.gov/pmc/articles/ PMC4420570/.

WHO. (2016). Diabetes. [artikel] World Health Organization. Diakses dari http://www.who.int/ mediacentre/factsheets/fs312/en/. 